\title{
How Education can help Solve Huge Perinatal Problems in Africa
}

\section{José M Carrera}

\begin{abstract}
We begin this article stating the dramatic situation of perinatal medicine in Africa. Then we revise the problems derived from the poor education of the population regarding reproductive health, the limited number of maternal and infant health professionals and their lack of technical training. We especially focus on the problems of standardizing the use of ultrasound in obstetrics and perinatal medicine. Finally, we insist on the role of education for professionals and for the people in general, as a tool to improve perinatal results.
\end{abstract}

Keywords: Education and health, Education in reproductive health, Perinatal problems and education.

How to cite this article: Carrera J M. How Education can help Solve Huge Perinatal Problems in Africa. Donald School J Ultrasound Obstet Gynecol 2013;7(3):292-295.

Source of support Matres Mundi NGO

Conflict of interest: None declared

\section{PERINATAL PROBLEMS IN AFRICA}

A frica is, no doubt, the continent with the most health problems, particularly those referring to mother and child health care. This is especially true for sub-Saharan A frica where maternal mortality rates are 90 times higher than in European countries. Perinatal mortality rates are 30 times higher and infant mortality rates are 20 times higher (Table 1).

According to the WHO, A frica has $24 \%$ of the world's disease burden but only $3 \%$ of the world's health workforce to deal with it. While in Europe there is a doctor for every 330 people, in sub-Saharan A frica there is only one for every 20,000 people. ${ }^{1} A$ nd the same happens with midwives and nurses (Table 2). A s a consequence of this lack of resources and the bad economic situation of these countries $47 \%$ of children younger than 5 suffer from under nourishment and the infant mortality rate is $160 / 100,000$ live births (LB). ${ }^{2}$

\begin{tabular}{|c|c|c|}
\hline & Global Africa & $\begin{array}{l}\text { Sub-Saharan } \\
\text { Africa }\end{array}$ \\
\hline $\begin{array}{l}\text { Maternal mortality per } \\
100,000 \text { LB }\end{array}$ & 620 & 900 \\
\hline $\begin{array}{l}\text { Maternal mortality by } \\
\text { unsafe abortion per } 100,000 \text { LB }\end{array}$ & 400 & 600 \\
\hline $\begin{array}{l}\text { Perinatal mortality } \\
\text { per } 1,000\end{array}$ & 100 & 160 \\
\hline Infant undernutrition per 100 & 80 & 120 \\
\hline Low birthweight per 100 & 22 & 47 \\
\hline Obstetric fistula (millions) & 20 & 24 \\
\hline
\end{tabular}

\begin{tabular}{lcl}
\multicolumn{4}{c}{ Table 2: Deficits in sanitary resources ${ }^{1,2,4,5}$} \\
\hline & Global & $\begin{array}{l}\text { Sub- } \\
\text { Africa }\end{array}$ \\
& & $\begin{array}{l}\text { Sa haran } \\
\text { Africa }\end{array}$ \\
\hline Doctors per 10,000 inhabitants & 2 & 0.5 \\
Midwives and nurses per 10,000 inhabitants & 11 & 2 \\
Hospital beds per 10,000 inhabitants & 9 & 3 \\
Delivery care coverage per 100 & 40 & 20 \\
Water supply per 100 & 40 & 20 \\
Births without register per 100 & 71 & 90 \\
Budget to health (\% government budget) & $>10$ & $<3$ \\
\hline
\end{tabular}

The main reasons that explain this situation are: (a) poverty (due to colonial plundering and the chronic lack of resources), (b) corruption and negligence of factual powers, (c) structural deficit (limited budget for the Department of Health), (d) cultural and social déficit (people with poor or inexistent education on reproductive health) and (e) limited number of mother and infant health professionals.

\section{CURRENT SITUATION OF POPULAR AND PROFESSIONAL EDUCATION ON REPRODUCTIVE HEALTH}

\section{Information and Popular Education on Reproductive Health}

M ost sub-Saharan A frican population have scarce or no information on reproductive health. This is due to several facts: (a) illiteracy ( $70 \%$ of illiterate people are women); (b) low government budget on education; (c) cultural prejudices, especially in rural areas ( $80 \%$ of the population); (d) chronic sexual discrimination on education (in many countries education is limited to boys) and (e) social exclusion of women because they are not allowed to take their own decisions (Table 3 ). ${ }^{3}$

This lack of education on reproductive heal th, together with several cultural factors, explains that over $20 \%$ of pregnant women are adolescents (younger than 16). In some countries like Somalia, for example, the figure exceeds $40 \%$. Only between 10 and $15 \%$ of these pregnancies have the necessary prenatal control (Table 4).

B esides, being pregnant means leaving school and giving up any socioeconomic project.

\section{Level of Training of Health Professionals}

As we have al ready mentioned, A frica has a dramatic deficit in human and structural resources to provide quality heal th 
How Education can help Solve Huge Perinatal Problems in Africa

\begin{tabular}{lc}
\hline \multicolumn{2}{c}{ Table 3: Illiteracy in Africa (\% of inhabitants) } \\
\hline Region & $\%$ \\
\hline Northern Africa & 35.84 \\
Western Africa & 55.87 \\
Central Africa & 40.98 \\
Eastern Africa & 40.18 \\
Southern Africa & 25.13 \\
\hline
\end{tabular}

The $70 \%$ of the illiterate are women (S ource: UNESCO, 2010)

Table 4: Adolescent mother (<16 years old). Early marriage, pregnancy and prenatal care

\begin{tabular}{lcc}
\hline & Global Africa & $\begin{array}{l}\text { Sub-Saharan } \\
\text { Africa }\end{array}$ \\
\hline Child marriage & $30 \%$ & $40 \%$ \\
Adolescent mothers & $10-15 \%$ & $>20 \%$ \\
Perinatal care & $25 \%$ & $<15 \%$ \\
\hline
\end{tabular}

Source: UNICEF (2009), World Bank (2011)

care. This deficit is especially severe in sub-Saharan A frica (Table 2). In some countries such as Ethiopia and Somalia the lack of physicians is very serious ( 1 per 40,000 people). Midwives, essential to offer a minimum perinatal assistance are less than 1 per 10,000 people. As a consequence only $10 \%$ of women from these countries give birth in a hospital. ${ }^{1}$

The causes of the scarce number of health professionals are: (a) shortage of medical schools ( 1 for every 5 million people) and most of them badly equipped. ( $80 \%)$; (b) the emigration of professionals to other countries (especially Europe and the USA ) looking for better life conditions. The sub-Saharan A frica Medical School Study ${ }^{4}$ reports that 5 years after graduation $23 \%$ of the doctors have left A frica (Fig. 1). This means that during the last 3 decades a million professionals emigrated to developed countries. There are more doctors from B enin in France than in B enin. A nd there are more doctors from Sierra L eone in Chicago than in Sierra Leone. Something similar happens in Ethiopia and other neighboring countries.

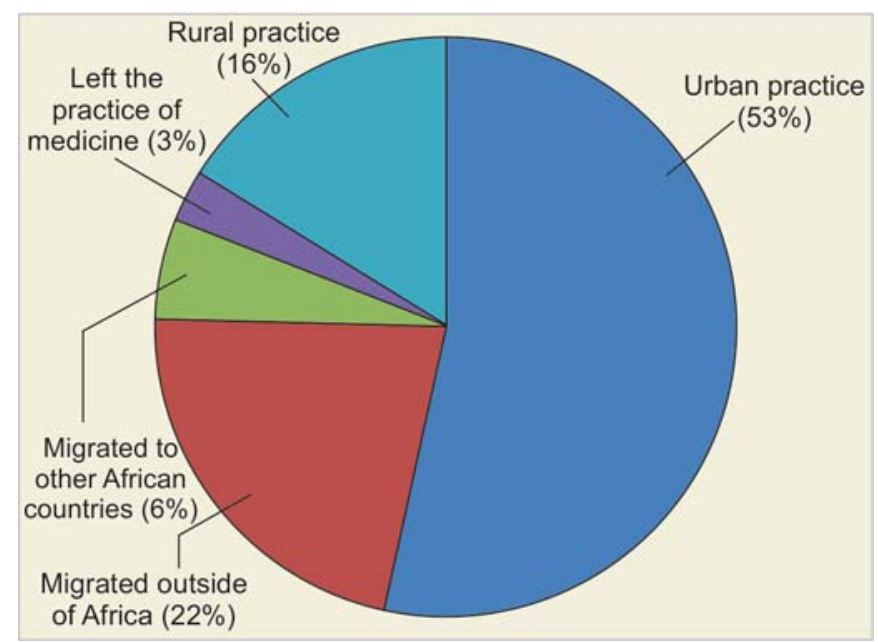

Fig. 1: Estimated location of doctor 5 years after graduation ${ }^{4}$
Moreover, the level of training of the few local professionals there is usually inadequate and they have no updated technology resources.

\section{Level of Training in Ultrasonography}

It is difficult to know exactly the situation of perinatal ultrasonography in some A frican countries. A study carried out by $M$ atres $M$ undi volunteers in 20115 shows that subSaharan A frica is the area where the shortage of ultrasound professionals is highest.

North A frican countries (M orocco, Tunisia, Egypt, etc.) have significant prenatal coverage that includes and ultrasound scan. In urban areas $88 \%$ of pregnant population has been given, at least, one. However, the figures are particularly low in rural areas where $84 \%$ of expectant mothers are not given any ultrasound at all (T able 5).

The situation is much worse in sub-Saharan A frica. In countries such as M ali, M auritania, Niger, Chad, etc. most pregnant women do not even know what an ultrasound is.

However, in Southern Africa, particularly in the Republic of South A frica, the situation improves somewhat in urban areas where around $58 \%$ of expectant mothers have had, at least, one ultrasound scan.

The theoretical and practical training provided to the health professionals who perform obstetric scans in A frica is generally low quality. Ultrasound is an operatordependent technique. Therefore, the results depend crucially on the sonographer's knowledge and experience. In A frica very few practitioners receive a practical course or learn the technique in a hospital environment. It is therefore understandable that the results are very poor (Table 6).

Unfortunately, in many parts of A frica, whether for cultural or financial reasons, the introduction of ultrasound

Table 5: P renatal ultrasonography in Africa

\begin{tabular}{lcccc}
\hline & \multicolumn{2}{c}{ Urban area } & \multicolumn{2}{c}{ Rural area } \\
\hline $\begin{array}{l}\text { Geographical } \\
\text { area }\end{array}$ & 1 exam & $\geq 3$ exam & 1 exam & $\geq 3$ exam \\
\hline North Africa & $88 \%$ & $23 \%$ & $16 \%$ & $3 \%$ \\
Sub-Saharan Africa & $22 \%$ & $5 \%$ & $2 \%$ & $0 \%$ \\
Southern Africa & $58 \%$ & $28 \%$ & $18 \%$ & $4 \%$ \\
\hline
\end{tabular}

Source: Matres Mundi ${ }^{5}$

Table 6: Training of sonologists in Africa

\begin{tabular}{lc}
\hline Type of training & Percentage \\
\hline Short course (theoretical) & 40.4 \\
No training & 38.3 \\
Practical course & 14.9 \\
Self-study & 6.4 \\
In service training & 2.1 \\
\hline
\end{tabular}

Source: Foulkes S et al (2004) 
has caused a considerable number of problems. The lack of practitioners' adequate training leads to misinterpret scans and as a consequence there is an unjustified rise in obstetric and gynecological surgery procedures. Frequently the market forces dominate instead of health requirements. Too much ultrasound is performed unnecessarily, while other important aspects (blood pressure, for example) are neglected.

\section{African Societies and Scientific Production}

A number of different ul trasound societies and associations have been created in A frica in recent years. A part from some considerable active national societies, a number of different continental and regional societies have been formalized (A frican Society of Radiology and U Itrasonography, South A frica Society of UItrasounds, M editerranean and A frican Society of UItrasounds, West A frican M edical UItrasound Society, etc.).

A bout Obstetrics Schools of Ultrasound we have to highlight the significant work being done by the Ian Donald School which runs different-level courses across the whole continent and has branches in Sudan, Egypt, Tunisia, Libya, Cameroon, Ghana, Ethiopia, etc. ${ }^{13}$

Finally the foundation of the 'International School of Perinatal M edicine for A frica' ${ }^{14}$ supported by the majority of International Societies of Perinatal M edicine will improve the quality of training.

Despite the fact that $A$ frica continues to be the continent with the lowest production of scientific work, the situation has now changed. In the last 10 years no fewer than 1,000 papers regarding obstetric ultrasound have been published in national and international journals. Some of the papers are very good, and there are new specialized African journals.

\section{WAYS TO IMPROVE PERINATAL RESULTS IN AFRICA THROUGH EDUCATION}

\section{The Role of Education on the Population in General}

One of the most successful ways to improve reproductive health of A frican population is to increase their education, especially sexual health education, by promoting the use of contraceptive methods and delaying marriage age. ${ }^{19}$

There is a significant connection between education, reproductive heal th knowledge and the use of contraceptive methods. W hile $45.9 \%$ of women with secondary education adopt modern and effective family planning methods, only $9.8 \%$ of women with no education adopt them (Table 7 ). Similarly, as school attendance is much higher in urban areas
Table 7: Characteristics of currently married women according to the practice of family planning (E thiopia, 2005)

\begin{tabular}{ll} 
according to the practice of family planning (E thiopia, 2005) \\
\hline Age of women \\
$15-19$ & $8.5 \%$ \\
$20-24$ & $15.4 \%$ \\
$25-29$ & $16.2 \%$ \\
$30-34$ & $13.7 \%$ \\
Education & \\
No education & $9.8 \%$ \\
P rimary & $21.9 \%$ \\
Secondary and higher & $45.9 \%$ \\
Place of residence & \\
Urban & $10.5 \%$ \\
Rural & $42.2 \%$ \\
\hline
\end{tabular}

Source: Akililu Demissie ${ }^{6}$

than in rural areas, the use of contraceptive methods is four times higher in cities (42.2\%) than in rural areas (10.6\%). . $^{6-8}$

Unfortunately the youngest married women ${ }^{15-19}$ are the ones that use contraception less $(8.6 \%)$ whereas more women over 25 use it ${ }^{16}(20 \%)$.

No doubt, family planning is one of the most effective instruments to reduce maternal and perinatal mortality. ${ }^{18}$

Early marriages usually lead women to give up school and social, economic and cultural prospects. ${ }^{9-12}$ Delaying marriage has also a positive effect on education. If a girl marries at 18 or later she will be able to complete primary education and improve her knowledge on family planning and reproductive health in general. In this case, the first pregnancies can be faced in a more rational way, substantially improving perinatal results. $2,9,17,19$

Local governments should also make an effort to improve their GNP increasing the budgets for education and health care. A ccording to the W orld Bank data (2002, 2010), if the increase in GNP was focused on education maternal and perinatal mortality rate would reduce by $10 \%$ and child mortality rate by 2 to $4 \%$.

\section{The Role of Education and Training of Health Professionals}

Because of the above-mentioned reasons, in A frica the number of maternal-infant health professionals is scarce and their level of education and training is usually low. There is a connection between the number of health professionals and perinatal results. In N orthern A frica (M orocco, Tunisia, A lgeria, etc.) and in Southern A frica where the number of physicians is higher than 4 per 10,000 people, perinatal results are clearly better than those in sub-Saharian A frica where the number of physicians is 0.5 per 10,000 people.

The WHO and several other NGOs have worked hard to increase these ratios. They have implemented regional programs, they have set up schools of medicine and they have helped those al ready existing that were worse 
equipped. They have also planned courses for empirical midwives and updating courses for specialists in reproductive health, general practitioners and qualified midwives.

At the beginning, the WHO was in favor of retraining traditional midwives but the dramatic maternal and perinatal mortality rates have not improved.

A nother necessary action is to increase the number of publications on reproductive health for professionals adapted to A frican context.14,15

The most recent attempt to increase significantly the number of health professi onals in A frica has been promoted by the International School of Perinatal M edicinefor A frica, a nonprofit entity supported by all the International Societies of Perinatal M edicine (IA PM , W A PM , EA PM , A A PM , etc.) and managed by MATRES MUNDI an international NGO specialized in maternal-infant health. ${ }^{16}$

\section{The Role of Education and Training in Ultrasound}

All the actions focused on ultrasound education and training mentioned in section 2.3 , have considerably improved the level of training in ultrasonography of A frican obstetricians and perinatologists and have overcome some of the problems that have hindered the implementation of this technique in A frica: (a) bad economic situation, (b) cultural resistance, (c) lack of electricity supply, (d) lack of local training system, etc.

Some of the dangers derived of the incorrect use of ultrasonography such as: (a) absence of any type of control regarding operators and equipment, (b) lack of practitioner training, (c) unjustified rise in obstetric and gynecological surgery procedures, (d) commodification of obstetric ultrasound, etc. ${ }^{5}$ have diminished; thanks to specific professional societies that have developed guidelines and protocols and, above all, thanks to the co-operation of international schools, such as the Ian Donald School that provide theoretical and practical courses and settle in every country through national branches.

In those A frican countries where ultrasonography has been introduced correctly, according to international regulations and with well trained ultrasonographers, perinatal results have improved.

\section{CONCLUSION}

We can state that education on reproductive health for the population in general and the increase in number and training of health professionals (midwives, obstetricians, pediatricians, nurses, etc.) is basic to improve perinatal medicine in A frica and reduce the high rates of maternal, perinatal and infant mortality.

\section{REFERENCES}

1. W orld Health Organization. Heal th situation analysi sintheA frican region. A tlas of $\mathrm{H}$ ealth Statistics. W orld Health Organization: regional office of A frica. B razzaville; 2011. 1-99 p.

2. Red A ctivas. A yuda eficaz para mejorar la salud y los derechos sexuales y reproductivos. Etiopia-N iger-Senegal. M adrid; 2010. 7-111 p.

3. Caldwell J C, Caldwell P. The cultural context of high family in sub-Saharan A frica. Population Develop Rev 1987 Sep;13(3): 409-437.

4. Bill and M elinda Gates Foundation: The sub-Saharan A frican Medical School Study; 2011.

5. M atres $M$ undi International. Report about "use and misuse of ultrasound in A frica". FIGO W orld Congress. Roma; 2012.

6. Demissie A. Factors influencing the practice of modern family planning methods among married women in Ethiopia: evidence from 2005 Ethiopian D emographic and Heal th Survey. Ethiopian J Reprod Health 2012;6(1):4-13.

7. Cleland JG, Ndugwa RP, Zulu EM. Family planning in subSaharan A frica: progress or stagnation. Bull W orld Heal th Organ 2011 N ov;89(2):137-143.

8. Caldwell JC. M ass education as determinant of the timing of fertility decline. Population Develop Rev 1980 J un;6(2): 225-255.

9. M uthengi $E$. Early marriage and female schooling in Ethiopia. Ethiopian J Reprod Health 2012;6(1):46-55.

10. Jejcebhoy SJ. Education and women's age at marriage. In: J ejcebhoy SJ, editor. Women's education, autonomy and reproductive behavior: experience from developing countries. England, Oxford: Clarendon Press; 1995. 60-77 p.

11. Brown G. Out of wedlock, into school: combating child marriage through education. UK, London: Office of Gordon and Sara Brown; 2012. 3-32 $p$.

12. Nour N . Heal th consequences of child marriage in A frica. Emerg Inf Dis $2006 \mathrm{~N}$ ov;12(11):1644-1649.

13. $M$ atres $M$ undi International. I an Donald School: past, present and future. Chapter 4: World Ian Donald School Branches. A ctivities and Directors. Spain: B arcelona; 2009. 51-150 p.

14. Matres $M$ undi International. Basic perinatal care. Graphic training program. Spain: B arcelona; 2009. 5-151 p.

15. $M$ atres $M$ undi International. Recommendations and guidelines for perinatal medicine in developing countries. Spain: B arcelona; 2007. 9-456 p.

16. $M$ atres $M$ undi. International School of perinatal medicine for A frica. Report of foundation. Spain: B arcelona; 2013.

17. Desai S, A Iva S. M aternal education and child health: is there a strong causal relationship? Demography 1998 Feb;35(1):71-78.

18. M bizvo MT, Saye L. Global progress and potentially effective responses to reduce maternal mortality. Int J Gynecol Obstet 2012 Oct; 119(Suppl 1):S9-S12.

19. K arlsen S, Say L, Souza JP, Hogue CJ , Calles DL, Gülmezogen $A M$, Raine $R$. The relationship between maternal education and mortality among women giving birth in health care institutions: analysis of the cross-sectional W HO G lobal Survey on M aternal and Perinatal Health. B M C Public Health 2011 J ul;11:606.

\section{ABOUT THE AUTHOR}

\section{José M Carrera}

President of $M$ atres $M$ undi

Correspondence Address: Ganduxer, Ático 8, 08021 Barcelona Phone: 0034626482 287, e-mail: jmcarrera@ matres-mundi.org 